\title{
Spectrophotometric Determination of Salbutamol Sulphate and Mefenamic Acid Using Azur-A Dye in Presence of Oxidizing Agent N-bromosuccinimide
}

\author{
Asmaa Hamza Abbas Al-Hashemi ${ }^{1 *}$, Subhi Mohsin Jarullah Al-Mtwaiti ${ }^{2}$ \\ 1,2Department of Chemistry, College of Education for Pure Sciences, University of Mosul, Mosul, Iraq \\ E-mail: ${ }^{*}$ asom92@gmail.com, ${ }^{2}$ drsubhi74@uomosul.edu.iq
}

(Received May 13, 2020; Accepted August 22, 2020; Available online December 01, 2020)

DOI: 10.33899/edusj.2020.127113.1072, (c) 2020, College of Education for Pure Science, University of Mosul.

This is an open access article under the CC BY 4.0 license (http://creativecommons.org/licenses/by/4.0/).

\begin{abstract}
A simple, accurate and sensitive indirect spectrophotometric method has been developed for the determination of salbutamol sulphate and mefenamic acid in pure forms and in pharmaceutical preparations (capsule, syrup, tablet). This method based on the bromination of the drug with $\mathrm{N}$ bromosuccinimide in acidic medium and the unreacted oxidizing agent react with constant amount of Azur-A dye solution due to bleach their colour and measured the absorbance of the residual colour dye at $606.5 \mathrm{~nm}$. The molar absorptivity for salbutamol sulphate and mefenamic acid are $2.3 \times 10^{4}{\mathrm{~L} . \mathrm{mol}^{-}}^{-}$ ${ }^{1} . \mathrm{cm}^{-1}$ and $8.1 \times 10^{3} \mathrm{~L} \cdot \mathrm{mol}^{-1} \cdot \mathrm{cm}^{-1}$ respectively. Beer's Law was obeyed over the concentration range of $1.6-12.8 \mu \mathrm{g} / \mathrm{ml}$ for salbutamol sulphate and $1.6-13.6 \mu \mathrm{g} / \mathrm{ml}$ for mefenamic acid. The limit of detection (LOD) were $0.0367 \mu \mathrm{g} / \mathrm{ml}$ and limit of quantitation (LOQ) were $0.1226 \mu \mathrm{g} / \mathrm{ml}$ for both drugs. In addition, the recovery levels of the drugs were in the range $100.56 \%$ and $100.74 \%$. The method was created to be simple, cost-effective and rapid because it does not involve any solvent extraction. The developed method was successfully applied for the determination of the studied drugs.
\end{abstract}

Keywords: Spectrophotometry; Salbutamol Sulphate; Mefenamic Acid; Azur-A Dye; Nbromosuccinimide.

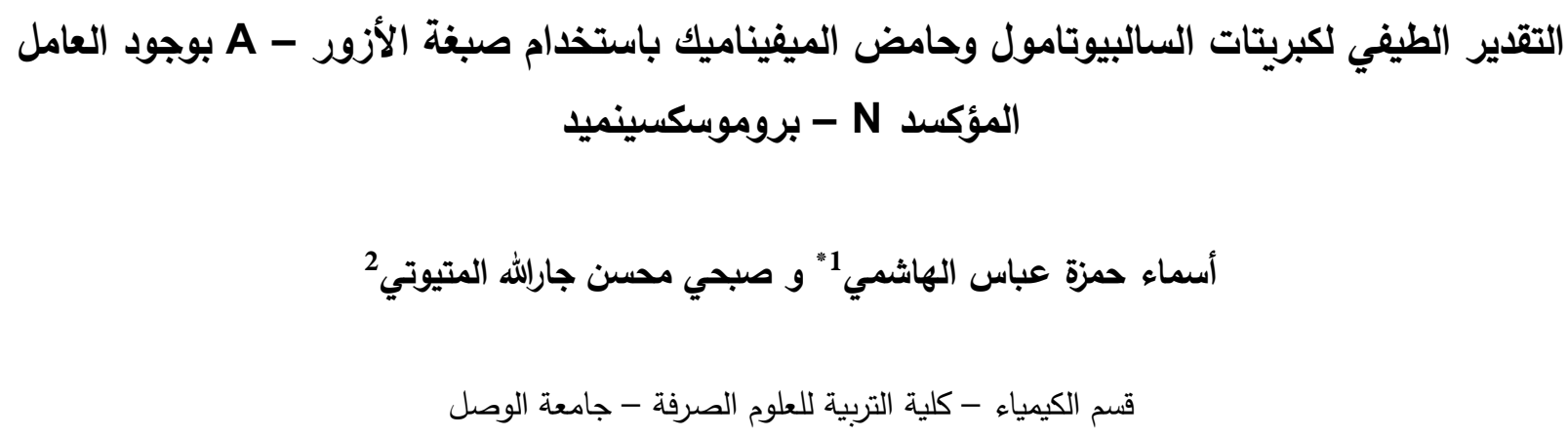


الخلاصة

طورت طريقة طيفية غير مباشرة سهلة ودقيقة وحساسة لتقدير كبريتات السالبيوتامول وحامض الميفيناميك بثكليهما النقي

وفي المستحضرات الصيدلانية (اقراص، شراب، كبسول) اعتمدت الطريقة على برومة المركب الدوائي بوجود العامل المؤكسد Nبروموسكسينميد (NBS) في الوسط الحامضي وتقدير غير المتفاعل من العامل المؤكسد عن طريق تفاعله مع كمية ثابتة من محلول صبغة الأزور - مؤدياً إلى قصر لونها فيقاس امتصاص المتبقي منها عند طول موجي 606.5 نانوميتر لكلا الدوائين. بلغت

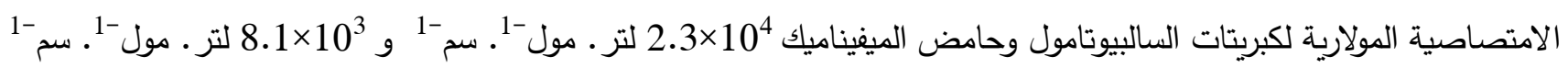
على التوالي. حدود قانون بير كانت ضدن مدى التراكيز 1.6 - 12.8 مايكروغرام/مللتر لكبريتات السالبيوتامول و - 13.6 6.مايكروغرام/مللتر لحامض الميفيناميك. بلغ حد الكثف (LOD) 0.0367 مايكروغرام/مللتر وبلغ حد التقدير الكمي (LOQ) 0.1226 مايكروغرام/مللتر لكلا الدوائين وبمعدل نسبة استرجاع 100.56\% و100.74\% لكبريتات السالبيوتامول وحامض الميفيناميك على التوالي. استحدثت الطريقة لتكون بسيطة، غير مكلفة وسريعة لكونها لا تتضمن اي استخلاص بالمذيبات. طبقت الطريقة بنجاح على المستحضرات الصيدلانية. الكلمات المفتاحية: التقدير الطيفي، كبريتات السالبيوتامول، حامض الميفيناميك، صبغة الأزور -A N-Nبروموسكسنميد. المقدمة Salbutamol sulphate كبريتات السالبيوتامول ان دواء كبريتات السالبيوتامول يستعمل كموسع قصبات وهو من عائلة أدوية الأدرينالين حيث يعمل على ارخاء العضلات المحيطة بالثعب الهوائية، ويستعمل في حالات ضيق الجهاز التنفسي وكذلك حالات الربو المزمنة كما يستخدم أيضاً في التقليل من حالات الولادات المبكرة [1] ، وكغيره من الأدوية فإن له اعراضاً جانبية منها تسارع نبضات القلب وانخفاض ضغط الدم وارتفاع مستوى السكر في الدم بالإضافة إلى النعاس الثديد والصداع [2]. إن دواء كبريتات السالبيوتامول متوفر في الاسواق بشكل أقراص وبخاخ وكذلك شراب. ويفضل عدم استخدامه للنساء الحوامل والمرضعات إلا باستشارة الطبيب ويمتلك كبريتات السالبيوتامول الصيغة الكيميائية التالية [5,4,3]: 


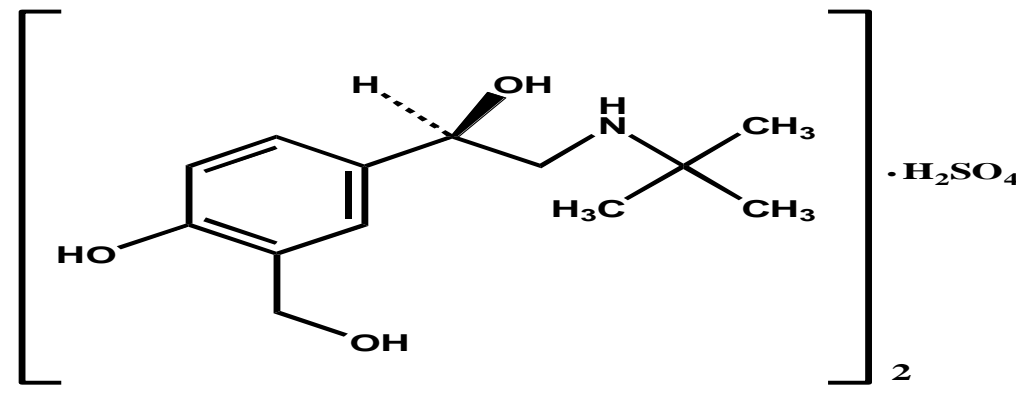

Salbutamol Sulphate $\left(\mathrm{C}_{26} \mathrm{H}_{44} \mathrm{~N}_{2} \mathrm{O}_{10} \mathrm{~S}\right)$

RS-4-[2-(tert-butylamino)-1-hydroxyethyl]-2-(hydroxymethyl)phenol sulphate

Molar mass $=576.702 \mathrm{~g} / \mathrm{mol}$

Mefenamic Acid حامض الميفيناميك

حامض الميفيناميك او 2- (2، 3 - ثنائي مثيل فنيل) أمينو حامض البنزويك، وهو دواء غير سترويدي مضاد للالتهاب المعروف تجارياً باسم Ponstan أو Ponstel [6]، ( Non-steroidal anti-inflammatory drug , NSAID) ويستعمل طبياً خافضاً للحرارة ومضادا للالتهابات ويتم وصفه مسكناً للالام ويستعمل لمعالجة بعض الامراض الثائعة مثل التهاب المفاصل الضموري (Osteoarthritis) والتهاب المفاصل الروماتزمي (Rheumatoid arthritis) [7]. له قابلية أقوى من الاسبرين في فاعلية تسكين الألم وأقل خطراً من ناحية الإصابة بقرحة المعدة، حيث يعادل 250 ملغم منه 600 ملغم من الاسبرين [8]. فاعلية حامض الميفيناميك تكمن في تأثيره على البروستاكلاندينات (Prostaglandines) والتي هي عبارة عن مركبات تتكون داخل الجسم عند اصابة الثخص بجروح أو نتيجة تعرضه لحالات مرضية معينة مسببة الماً وانتفاخاً والتهاباً في موقع الاصابة إذ يعمل الدواء على ايقاف تكوين هذه المركبات (البروستاكلاندينات) [9]. يمتلك حامض الميفيناميك الصيغة التركيبية التالية [5]:

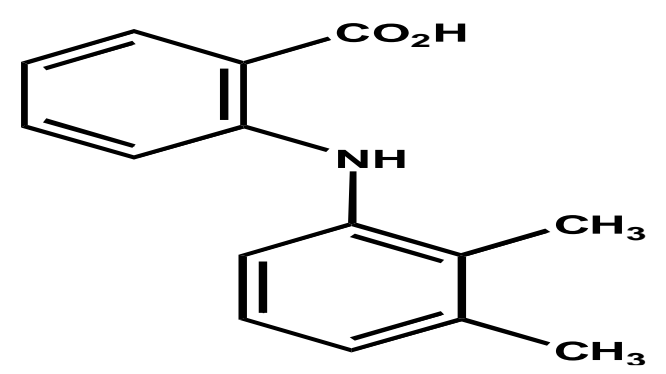

Mefenamic Acid $\left(\mathrm{C}_{15} \mathrm{H}_{15} \mathrm{NO}_{2}\right)$

2-(2,3-Dimethylphenyl) aminobenzoic acid

Molar mass $=241.3 \mathrm{~g} / \mathrm{mol}$

وصفت طرائق تحليلية مختلفة لتقدير المركبين الدوائيين قيد الدراسة، إذ تم تقدير كبريتات السالبيوتامول طيفيا بالاعتماد على

تفاعلات الأكسدة والاختزال [10] وتفاعلات الاقتران التأكسدي [11]، كما قدر بمفاعلته مع كاشف بارا- فنيلين ثنائي الأمين باستعمال 
ميتابيريودات الصوديوم كعامل مؤكسد [12]، وقدر باستخدام تفاعلات الثحنة المنتقلة [13]، وأيضاً قدر كهربائيا باستخدام طريقة القياسات التوصيلية [14]، وقدر باستخدام طريقة كروماتوغرافيا السائل عالي الأداء - الطور العكوس [15]. نشرت طرائق طيفية حساسة لتقدير حامض الميفيناميك طيفياً بالاعتماد على تفاعلات الأكسة والاختزال [16] وتفاعلات الاقتران التأكسدي [17]، فضلاً عن التقدير الطيفي بالمنطقة فوق البنفجية اما بالاعتماد على فرق الدالة الحامضية pH [18] أو بتفاعله مع 1،2- نفثا كوينون-4- سلفونيك الصوديوم NQS [19]، وقدر في العينات البايولوجية اما بالاعتماد على التركيز المسبق باستخدام طبقة مزدوجة من النيكل والامنيوم- نانو هيدروكسيد Ni-Al-LDH [20] او باستخدام تقنية جزيئات نانو اوكسيد الحديد [21 Fe $\mathrm{Fe}_{3} \mathrm{O}_{4}$ ، وقدر باستخدام تقنية كروماتوغرافيا السائل عالي الأداء بالاقتران مع تقنية طيف الكتلة [22] وكروماتوغرافيا السائل

عالي الأداء - الطور العكوس [23]. وبالنظر لأهمية المركبين الدوائيين المدروسين فقد تم في هذا البحث اقتراح طريقة تحليلية غير مباشرة لتقدير كبريتات السالبيوتامول وحامض الميفيناميك في الوسط الحامضي باستخدام صبغة الازور -A بوجود العامل المؤكسد N - بروموسكسينميد. ان الهذف من هذا البحث هو تطوير طريقة طيفية سهلة ودقيقة وحساسة واقتصادية لتقدير المركبين الدوائيين في مستحضراتهما الصيدلانية. A- الاستعمالات التحليلية لصبغة الأزور

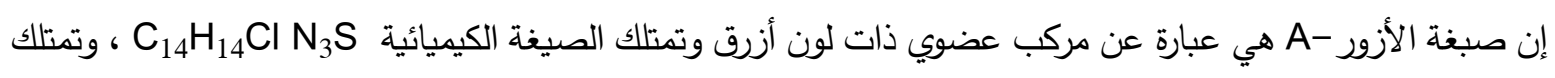
الصيغة التركيبية التالية [24]:<smiles>C[N+](C)=c1ccc2nc3ccc(N)cc3sc-2c1</smiles>

Azur-A Dye $\left(\mathrm{C}_{14} \mathrm{H}_{14} \mathrm{Cl} \mathrm{N} \mathrm{N}_{3} \mathrm{~S}\right)$

N-N-dimethylphenothiazin-5-ium-3,7-diaminechloride

Molar mass $=291.64 \mathrm{~g} / \mathrm{mol}$ ولصبغة الازور -A- تطبيقات تحليلية قليلة وهي قدرت كميات مايكروغرامية من أدوية البنسلين باستخدام هذه الصبغة إذ يتكون معقد مزدوج ايوني أزرق بين الصبغة ودواء البنسلين [24]. كذلك قدرت مركبات Sulfatides عن طريق تكوين معقد ملون بين Sulfolipids الأنيونية وبين صبغة الازور A الموجبة [25]. وأمكن تقدير كميات مايكروغرامية من المركب الدوائي كلوربرومازين هيدروكلوريد باستخدام هذه الصبغة بالاعتماد 
على تفاعلات الاكسدة والاختزال [26]. كذلك تم تقدير التتراسايكلين هيدروكلوريد بالاعتماد على تفاعلات الاكسدة والاختزال باستخدام هذه الصبغة [27]. الجزء العملي

\section{الأجهزة المستعملة}

تم استعمال جهاز المطياف الضوئي Double-spectrophotometer Shimadzu UV-1800 PC, UV-Visible مع خلايا كوارتز ذات عرض 1سم، كما تم تسخين المحاليل باستعمال حمام مائي نوع BS-11 Lab Companion-Korea، Elektro.mag واجري الوزن باستعمال ميزان حساس نوع KERN ABS-Germany، واستعمل جهاز المحرك المغناطيسي نوع

Thermo RL 060P Electron للحصول على افضل اذابة، وقيست الدالة الحامضية باستعمال جهاز قياس الدالة الحامضية .Company -Singapore المواد والمحاليل المستعملة

إن جميع المواد الكيميائية التي استخدمت كانت على درجة عالية من النقاوة.

محلول كبريتات السالبيوتامول: حضر بتركيز 100 مايكروغرام/ملتر باذابة 0.0100 غرام من المركب الدوائي بصيغته النقية في 10 مللتر ماء مقطر ثم أكمل الحجم إلى حد العلامة بالماء المقطر في قنينة حجمية سعة 100 ملتر . محلول حامض الميفيناميك: حضر بتركيز 100 مايكروغرام/ملتر باذابة 0.0100 غرام من المركب الدوائي بصيغته النقية في 2 مللتر من محلول 1 مولاري هيدروكسيد البوتاسيوم [5] ثم نقل إلى قنينة حجمية سعة 100 مللتر واكمل الحجم إلى حد العلامة بالماء المقطر . محلول صبغة الازور -A: حضر بتركيز 50 مايكروغرام/ملتر باذابة 0.0250 غرام من المادة في 200 مللتر من الماء المقطر مع التحريك المغناطيسي لمدة ساعة لغرض الحصول على افضل اذابة للصبغة ثم نقل المحلول إلى قنينة حمية سعة 500 مللتر واكمل الحجم إلى حد العلامة بالماء المقطر. محاليل العوامل المؤكسدة: حضرت العوامل المؤكسدة المستخدمة جميعها بتركيز 2×10 -3 مولاري وذلك بإذابة الكمية المناسبة من كل عامل بالماء المقطر في قنينة حجمية سعة 50 مللتر. محلول NBS: حضر بتركيز 5×10 -3 مولاري وذلك بإذابة 0.0889 غرام منه في 100 مللتر ماء مقطر ثم حضر من هذا التركيز بقية التراكيز الاقل بالتخفيف. 
محلول الحوامض المعدنية: حضرت المحاليل بتخفيف الكمية المناسبة من كل حامض مركز في قنينة حجمية سعة 100 مللتر بإضافتها الى الماء المقطر واكمال الحجم ايضاً بالماء المقطر إلى حد العلامة. محلول حامض الخليك: حضر بتركيز 3 مولاري وذلك بتخفيف 16.94 مللتر من الحامض المركز ذي التركيز 17.7 مولاري في 100 مللتر من الماء المقطر ثم حضر من هذا التركيز بقية التراكيز الاقل بالتخفيف. محلول هيدروكسيد الصوديوم: حضر بتركيز 1 مولاري بإذابة 4 غرام من المادة في 100 مللتر من الماء المقطر. محلول هيدروكسيد البوتاسيوم: حضر بتركيز 1 مولاري بإذابة 5.6 غرام من المادة في 100 مللتر من الماء المقطر . محاليل المواد الفعالة سطحياً: حضرت المحاليل بإذابة 0.1 غرام من كبريتات الصوديوم الدوديسالية (SDS) وسيتايل بيريدينيوم كلورايد(CPC) واذابة 1غرام من عامل الثد السطحي (Tween-80) و (Tween-20) كلا على حدة بالماء المقطر الساخن ومن ثم اكمل الحجم إلى حد العلامة بالماء المقطر في قنانٍ حجمية سعة 100 مللتر . طريقة العمل والمنحنيات القياسية اضيف إلى مجموعتين من قنانٍ حجمية سعة 25 مللتر كميات متزايدة 1.6- 12.8 و 1.6- 13.6 مايكروغرام/مللتر من كل دواء على حدة ومن ثم اضيف 1 مللتر من 2 مولاري حامض الخليك، ويليه اضافة 2 مللتر من 4 ×10 -3 مولاري من العامل المؤكسد N - بروموسكسينميد وتركت المحاليل مدة 10 دقائق ثم اضيف 18 مايكروغرام/ملتر من صبغة الازور -A، وبعد أن اكمل الحجم إلى حد العلامة بالماء المقطر تركت المحاليل في حمام مائي لمدة 5 دقائق عند درجة حرارة 25 مْ، قيست الامتصاصات للمحاليل مقابل محاليلها الصورية عند 606.5 نانوميتر . تحليل أقراص BUTADIN (كبريتات السالبيوتامول - 2 ملفم/مللتر) تم وزن عشرة أقراص من المستحضر الصيدلاني يحتوي القرص الواحد على 2 ملغم من كبريتات السالبيوتامول، طحنت ومزجت جيداً ثم اخذت جمعيها وتمت اذابتها في 150 مللتر من الماء المقطر وتركت على جهاز المحرك المغناطيسي لمدة ساعة ونصف حتى اكملت الاذابة جيداً, بعد ذلك رشح المحلول الناتج وأخذ الراشح واكمل الحجم بالماء المقطر في قنينة حجمية سعة 200 مللتر , إذ تم الحصول على تركيز 100مايكروغرام/مللتر من كبريتات السالبيوتامول, وتم ايجاد تركيز الدواء في كل قرص من المنحني القياسي لكبريتات السالبيوتامول بصيغته النقية . 


\section{محلول BUTADIN SYRUP (كبريتات السالبيوتامول - 2 ملفم /5 مللتر)}

اخذت قنينة دواء Butadin ذات محتوى 100 ملتر وسحب منها 25 مللتر التي تحتوي على 10 ملغم من كبريتات السالبيوتامول واكمل الحجم بالماء المقطر في قنينة حجمية سعة 100 مللتر للحصول على تركيز 100 مايكروغرام /ملتر من كبريتات السالبيوتامول، وتم ايجاد تركيز كبريتات السالبيوتامول في المستحضر باستخدام المنحني القياسي لكبريتات السالبيوتامول بصيغته

كبسول Mefstan (حامض الميفيناميك - 250 ملفم)

اخذت محتويات عشر كبسولات من المستحضر الصيدلاني ثم وزنت جميعها، ثم اخذ منها وزن كبسولة واحدة (المحتوية

على 250 ملغم من حامض الميفيناميك) ثم اضيف اليها 2 مللتر من هيدروكسيد البوتاسيوم و 250 مللتر من الماء المقطر وترك المحلول على جهاز المحرك المغناطيسي لمدة ساعة ونصف للحصول على افضل اذابة، ثم رشح المحلول واكمل الحجم بالماء المقطر في قنينة حجمية سعة 500 مللتر للحصول على تركيز 500 مايكروغرام /مللتر من حامض الميفيناميك، سحب منها 20 مللتر واكمل الحجم الى100 مللتر بالماء المقطر للحصول على تركيز 100 مايكروغرام/ مللتر وتم ايجاد تركيز الدواء في كل كبسولة من المنحني القياسي لحامض الميفيناميك بصيغته النقية.

\section{(أقراص 500 - Mefenamic Acid) PONAMEC ملفم)}

وزنت عشرة أقراص طحنت ومزجت جيداً ثم اخذ وزن قرص واحد المحتوي على 500 ملغم من حامض الميفيناميك، اضيف اليه 2 مللتر هيدروكسيد البوتاسيوم و200 مللتر من الماء المقطر وترك المحلول لمدة ساعة ونصف على جهاز المحرك المغناطيسي للحصول على افضل اذابة، رشح واكمل الحجم بالماء المقطر في قنينة حجمية سعة 250 مللتر للحصول على تركيز 2000 مايكروغرام/مللتر من حامض الميفيناميك خفف المحلول للحصول على 100 مايكروغرام/مللتر من المركب الدوائي وتم ايجاد تركيز الدواء في كل قرص من المنحني القياسي لحامض الميفيناميك بصيغته النقية. النتائج والمناقشة

الاراسة التمهيدية وطيف الامتصاص من أجل تطوير طريقة طيفية لتقدير كبريتات السالبيوتامول وحامض الميفيناميك اجريت تجارب عديدة لاختبار امكانية استخدام صبغة الأزور - A - (Aبالثكل التالي: 
تم رسم منحنى قياسي للصبغة لغرض ايجاد أكبر كمية من صبغة الأزور - تقع ضمن المدى الخطي للمنحني لقانون بير، تمت اضافة حجوم متزايدة 0.2 - 10 مللتر من الصبغة بتركيز 50 مايكروغرام /مللتر في قنانٍ حجمية سعة 25 ملتر ثم اكمل الحجم إلى حد العلامة بالماء المقطر فوجد ان الصبغة تعطي أقصى امتصاص عند 606.5 نانوميتر كما في الثكل (1) وأن المدى الخطي للصبغة 0.6 - 18 مايكروغرام/مللتر وان هناك انحرافا سلبيا بعد هذا المدى كما في الشكل (2)، وعليه استخدم التركيز 18 مايكروغرام/مللتر في الدراسات اللاحقة كونه كان أعلى قيمة خضعت لقانون بير، وبعد ذلك تم اختبار امكانية حدوث تفاعل أكسدة للصبغة بعد أخذ أعلى قيمة منها تخضع لقانون بير 18 مايكروغرام/مللتر في الوسط الحامضي او القاعدي باضافة 1 ملتر بتركيز 1مولاري من حامض الكبريتيك او هيدروكسيد الصوديوم باستخدام 3 مللتر بتركيز 2× 10 -3 مولاري من العامل المؤكسد Nبروموسكسينميد، إذ لوحظ قصر كمي للصبغة في الوسط الحامضي لذلك تم اضافة كميات مايكروغرامية من كلا الدوائين كبريتات السالبيوتامول وحامض الميفيناميك مع الكمية اعلاه من الصبغة في الوسط الحامضي وبوجود العامل المؤكسد في قنانٍ حجمية سعة 25 مللتر ومن ثم اكمل الحجم بالماء المقطر . اما عند استخدام الوسط القاعدي لوحظ تغير لون الصبغة وازاحة الطول الموجي إلى طول موجي اقصر لذلك اعتمد الوسط الحامضي. وبينت النتائج حدوث زيادة خطية في امتصاص صبغة الازور A عند 606.5 نانوميتر بزيادة تركيز كلا الدوائين وهذا يشير إلى امكانية اعتماد الطريقة في التقدير الطيفي الكمي للمركبين الدوائيين المدروسين.

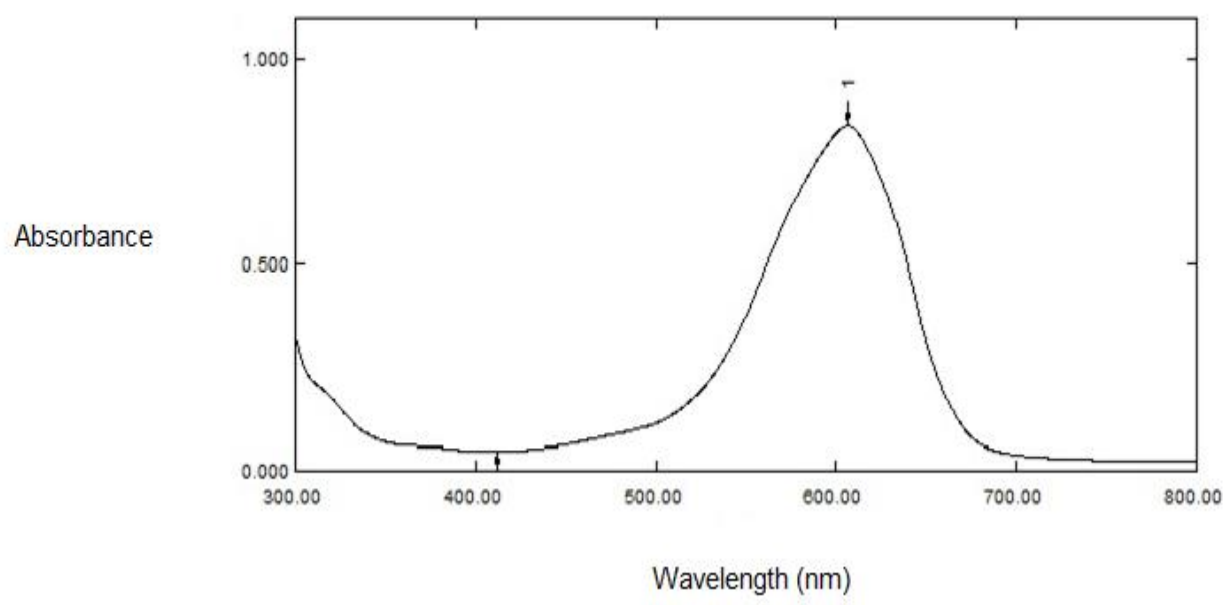

الثكل (1) طيف امتصاص 18 مايكروغرام/مللتر لصبغة الازور -A المذابة في الماء المقطر مقابل الماء المقطر 


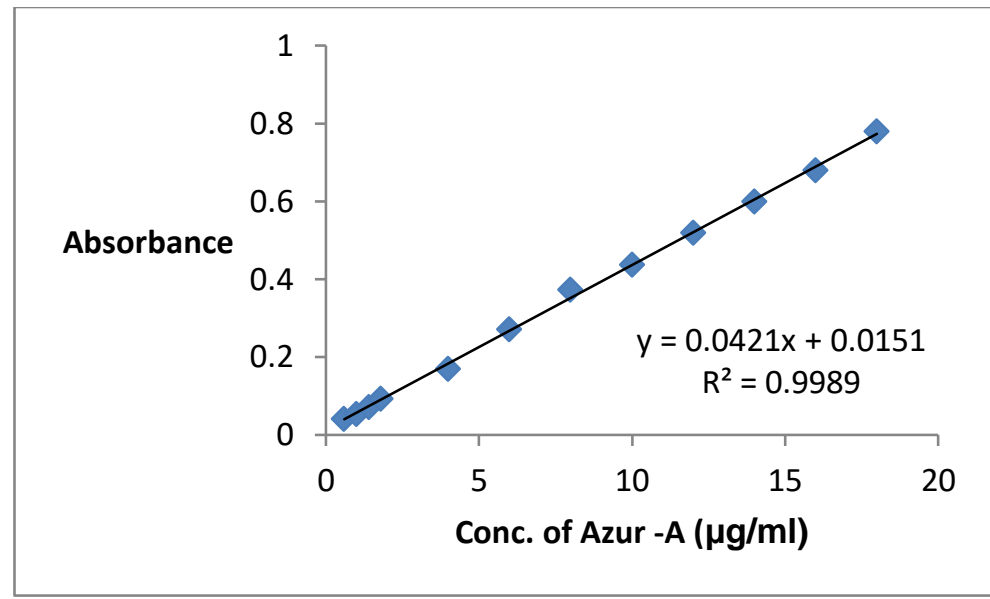

الثكل (2) المنحني القياسي لصبغة الأزور A في المحلول المائي

ضبط الظروف المثلى

تم اجراء دراسة الظروف المثلى باستخدام تركيز ثابت من كلا المركبين الدوائيين كبريتات السالبيوتامول وحامض الميفيناميك

8 مايكروغرام/مللتر في حجم نهائي 25 مللتر وتغيير احد المعطيات وتثبيت الاخرى ودراسة تأثيرها على امتصاص الصبغة.

A - تأثير نوع المذيب على امتصاص صبغة الازور

من اجل الحصول على اعلى امتصاص لصبغة الازور - فقد درس تأثير عدد من المذيبات القابلة للامتزاج مع الماء على

الامتصاص والمتمثلة بالإيثانول والميثانول والاسيتونترايل فضلاً عن الماء على كل من ذوبانية الصبغة والتخفيف، وذلك بإضافة الكمية المثلى من الصبغة 18 مايكروغرام/مللتر إلى قنانٍ حجمية سعة 25 مللتر تحتوي على 1ملتر حامض الكبريتيك بتركيز 1مولاري ثم اكمل الحجم إلى حد العلامة بالمذيب وقيس طيف امتصاص المحاليل ضد المحلول الصوري بعد خمس دقائق والجدول (1) يبين أن الماء هو الأنسب كونه أعطى أعلى امتصاص وعليه اعتمد في الدراسات اللاحقة. الجدول (1) تأثير نوع المذيب على امتصاص (18 مايكروغرام/ملتر) من الصبغة

\begin{tabular}{|c|c|c|}
\hline Solvents & $\lambda \max (\mathrm{nm})$ & Absorbance \\
\hline Ethanol & 608 & 0.636 \\
\hline Methanol & 610 & 0.755 \\
\hline Acetonitrile & 612.5 & 0.518 \\
\hline Water & 606.5 & 0.830 \\
\hline
\end{tabular}




\section{A - تأثير نوع العامل المؤكسد على امتصاصية صبغة الأزور}

في هذه الدراسة تم تحديد أفضل عامل مؤكسد يعطي أفضل قصر للصبغة عند تركيز 18 مايكروغرام/مللتر وذلك عن طريق مفاعلة الصبغة مع 3 مللتر من كل من العوامل المؤكسة التالية (N - بروموسكسينميد، كرومات البوتاسيوم، ثنائي كرومات البوتاسيوم، ايودات البوتاسيوم وبيريودات الصوديوم) وكانت جميعها محضرة بتركيز 2× 10 -3 مولاري وبوجود 1ملتر من 1مولاري حامض الكبريتيك وقيس الامتصاص بعد خمس دقائق من زمن التخفيف بالماء المقطر إلى حد العلامة في قنانٍ حجمية سعة 25 ملتر وعند درجة حرارة المختبر والتي كانت 15 مْه حيث يبين الجدول (2) أن افضل عامل مؤكسد اعطى افضل قصر لصبغة الازور - A- A - بروموسكسينميد NBS والذي تم اعتماده في الدراسة اللاحقة.

$$
\text { A - الجدول (2) تأثير نوع العامل المؤكسد على قصر صبغة الازور }
$$

Oxidizing agents

Absorbance

$$
2 \times 10^{-3} \mathrm{M}
$$

\begin{tabular}{cc}
\hline $\mathrm{NBS}$ & 0.166 \\
$\mathrm{~K}_{2} \mathrm{CrO}_{4}$ & 0.760 \\
$\mathrm{~K}_{2} \mathrm{Cr}_{2} \mathrm{O}_{7}$ & 0.779 \\
$\mathrm{KIO}_{3}$ & 0.798 \\
$\mathrm{NaIO}_{4}$ & 0.810
\end{tabular}

\section{ت تأثير تركيز العامل المؤكسد على قصر صبغة الازور}

تناولت هذه الدراسة افضل تركيز من العامل المؤكس NBS والذي يعطي افضل قصر للصبغة حيث اضيفت تراكيز مختلفة من العامل المؤكسد NBS إلى قنانٍ حجمية تحتوي على 18 مايكروغرام/مللتر من صبغة الازور - A و1 مللتر من 1 مولاري حامض الكبريتيك، وبعد اكمال الحجم إلى حد العلامة قيست الامتصاصات بعد خمس دقائق من زمن التخفيف عند درجة حرارة المختبر التي كانت 15 مّْ، وبينت الدراسة أن افضل تركيز هو 4×10 -3 مولاري لذلك تم اعتماده في الدراسة اللاحقة. A- الجدول (3) تأثير تركيز العامل المؤكسد NBS على قصر صبغة الازور

Concentration of NBS Absorbance

(M)

$\begin{array}{cc}0.5 \times 10^{-3} & 0.390 \\ 1 \times 10^{-3} & 0.207 \\ 2 \times 10^{-3} & 0.160 \\ 3 \times 10^{-3} & 0.155 \\ 4 \times 10^{-3} & 0.140 \\ 5 \times 10^{-3} & 0.144\end{array}$




\section{تأثير كمية العامل المؤكسد على قصر الصبغة}

A- بي هذه الدراسة تم تحديد الكمية المثلى من العامل المؤكسد بتركيز 18 مايكروغرام/مللتر وذلك بمفاعلتها مع كميات متزايدة من العامل المؤكسد NBS بتركيز 4×10 -3 مولاري وبوجود 1ملتر من 1مولاري حامض الكبريتيك، وبعد اكمال الحجم بالماء المقطر إلى حد العلامة في قنانٍ حجمية سعة 25 مللتر قيست الامتصاصات بعد خمس دقائق من زمن التخفيف لوحظ أن افضل كمية من NBS كانت عند 2 ملتر لذلك تم اعتماد هذا الحجم في الدراسات اللاحقة.

$$
\text { A- الجدول (4) تأثير كمية العامل المؤكسد A }
$$

\begin{tabular}{cc}
$\begin{array}{c}\text { Volume of NBS } \\
4 \times 10^{-3} \mathrm{M} \\
(\mathrm{ml})\end{array}$ & Absorbance \\
With out & 0.830 \\
0.5 & 0.209 \\
1 & 0.153 \\
1.5 & 0.152 \\
\hline 2 & 0.140 \\
2.5 & 0.142 \\
3 & 0.140 \\
3.5 & 0.141
\end{tabular}

A- تأثير نوع الحامض على قصر صبغة الازور بينت الدراسة التمهيدية أن اكسدة صبغة الازور - A بواسطة N- بروموسكسينميد تتم في الوسط الحامضي لذلك درس تأثير حوامض مختلفة في التقدير وذلك عن طريق اضافة كميات ثابتة 1 مللتر وبتركيز 1 مولاري من (CH كل على حدا إلى مجموعتين من قنانٍ حجمية تحتوي المجموعة الاولى على دواء كبريتات السالبيوتامول 8 مايكروغرام/ مللتر في حين تحتوي المجموعة الثانية على 8 مايكروغرام/ ملتر من دواء حامض الميفيناميك، وكانت كلا المجموعتين تحتوي على كميات ثابتة من صبغة الازور - 18 مايكروغرام/مللتر وبوجود 2 ملتر من 4×10 -3 مولاري من العامل المؤكسد NBS وبعد اكمال الحجم إلى حد العلامة بالماء المقطر في قنانٍ حجمية سعة 25 مللتر قيس الامتصاص بعد خمس دقائق لوحظ أن حامض الخليك اعطى أعلى امتصاص لكلا الدوائين لذلك اعتمد في الدراسة اللاحقة. 
الجدول (5) تأثير نوع الحامض المناسب في تقدير كبريتات السالبيوتامول وحامض الميفيناميك

Type of Acid

$(1 \mathrm{M})$

$\mathrm{HCl}$

$\mathrm{H}_{2} \mathrm{SO}_{4}$

$\mathrm{CH}_{3} \mathrm{COOH}$

$\mathrm{H}_{3} \mathrm{PO}_{4}$
Absorbance of Azur-A in presence of Salbutamol Sulphate Turbid

0.177

0.160
Mefenamic Acid

Turbid

0.232

0.408

0.259

تأثير تركيز وكمية حامض الخليك

بينت الدراسة في الجدول (6) والتي اجريت لتثبيت تركيز حامض الخليك عند تقدير كلا الدوائين كبريتات السالبيوتامول

وحامض الميفيناميك ان التركيز الانسب هو 2 مولاري من حامض الخليك لكلا الدوائين وعليه استخدم هذا التركيز في الدراسة

اللاحقة، ومن ثم اخذت حجوم متزايدة 0.5- 3 مللتر من حامض الخليك ذي التركيز 2 مولاري فوجد أن حجم 1 مللتر هو الانسب

كما يبين الجدول (7).

الجدول (6) تأثير تركيز حامض الخليك على امتصاصية الصبغة بوجود كبريتات السالبيوتامول وحامض الميفيناميك

Concentration of Absorbance of Azur-A in Presence of

$\mathrm{CH}_{3} \mathrm{COOH}(\mathrm{M}) \quad$ Salbutamol sulphate Mefenamic Acid

\begin{tabular}{ccc}
0.5 & 0.302 & 0.392 \\
1 & 0.301 & 0.409 \\
1.5 & 0.346 & 0.440 \\
\hline 2 & 0.358 & 0.440 \\
2.5 & 0.340 & 0.401 \\
3 & 0.336 & 0.398
\end{tabular}

الجدول (7) تأثير حجم حامض الخليك على امتصاص الصبغة بوجود دوائي كبريتات السالبيوتامول وحامض الميفيناميك

Volume of 2M Absorbance of Azur-A in Presence of

$\mathrm{CH}_{3} \mathrm{COOH}$ Salbutamol sulphate Mefenamic Acid (ml)

\begin{tabular}{ccc}
0.5 & 0.307 & 0.415 \\
\hline 1 & 0.359 & 0.445 \\
1.5 & 0.354 & 0.416 \\
2 & 0.354 & 0.427 \\
2.5 & 0.350 & 0.418 \\
3 & 0.352 & 0.414
\end{tabular}




\section{A- تأثير الزمن في اكسدة كبريتات السالبيوتامول وحامض الميفيناميك وصبغة الازور}

لمعرفة المدة الزمنية اللازمة لأكسدة المركبين الدوائيين المدروسين كبريتات السالبيوتامول وحامض الميفيناميك بواسطة العامل المؤكسد NBS فقد تم مفاعلة 8 مايكروغرام/مللتر من كل مركب دوائي مع كمية محسوبة من N - بروموسكسينميد (2 مللتر بتركيز 4×10 -3 مولاري) وبوجود الوسط الحامضي 1 ملتزر بتركيز 2 مولاري حامض الخليك وبأزمنة مختلفة وبعد اضافة الكمية المثلى من صبغة الازور - A (18 مايكروغرام/مللتر) وبالتخفيف بالماء المقطر إلى حد العلامة في قنان حجمية سعة 25 مللتر درس زمن اكسدة الصبغة بالكمية المتبقية من N - بروموسكسينميد واستقرارها عند درجة حرارة المختبر 15 مْ بقياس الامتصاص وادرجت النتائج في الجدول (8) و(9) إذ تبين النتائج أن الزمن اللازم لاكسدة المركبين الدوائيين كبريتات السالبيوتامول وحامض الميفيناميك كان عند 10 دقائق وقد تم اختيار الزمن 5 دقائق من اضافة الصبغة و التخفيف بالماء المقطر إلى حد العلامة لإجراء قياس امتصاص المحاليل إذ كان هذا الزمن كاف لأكسدة الصبغة.

$$
\text { A - الجدول (8) تأثير الزمن في أكسدة كبريتات السالبيوتامول وصبغة الازور }
$$

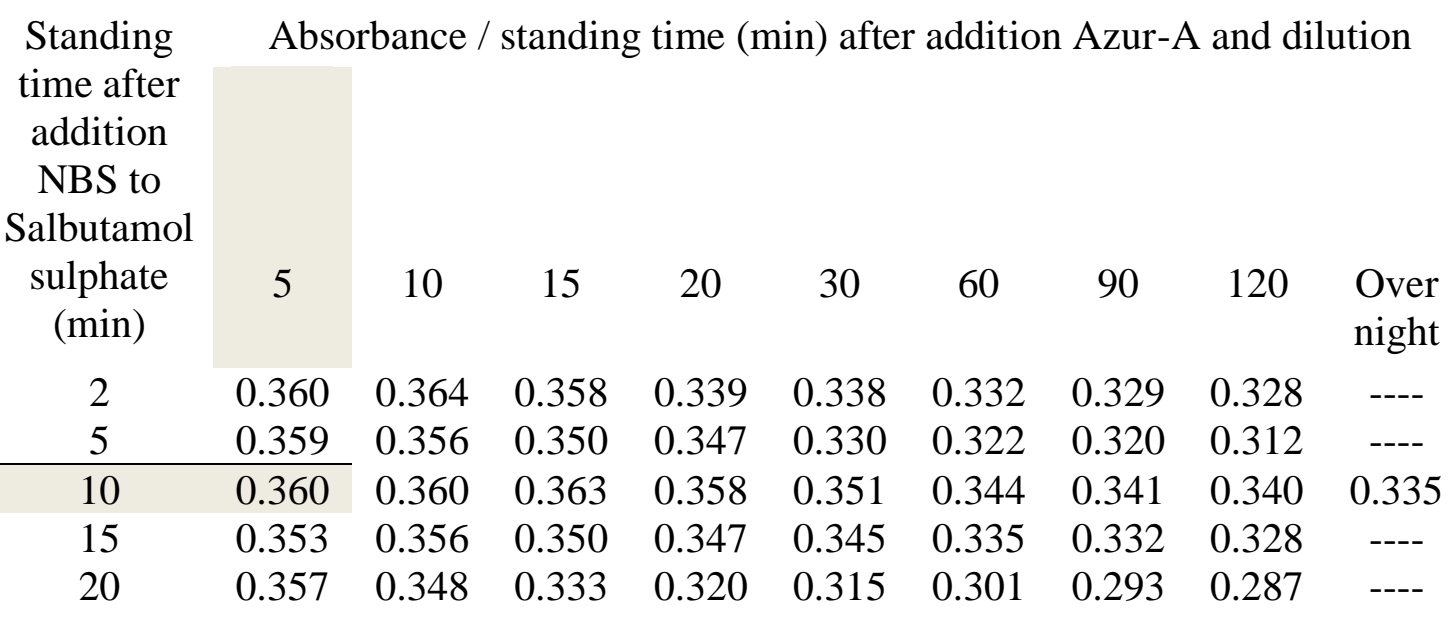

A- الجدول (9) تأثير الزمن في أكسدة حامض الميفيناميك وصبغة الازور

Standing Absorbance/standing time (min) after addition Azur-A and dilution time after addition NBS to

Mefenamic

\begin{tabular}{|c|c|c|c|c|c|c|c|c|c|}
\hline Acid (min) & 5 & 10 & 15 & 20 & 30 & 60 & 90 & 120 & night \\
\hline 2 & 0.444 & 0.439 & 0.437 & 0.423 & 0.417 & 0.401 & 0.403 & 0.397 & ---- \\
\hline 5 & 0.430 & 0.424 & 0.424 & 0.420 & 0.418 & 0.400 & 0.401 & 0.390 & \\
\hline 10 & 0.448 & 0.449 & 0.449 & 0.448 & 0.441 & 0.440 & 0.439 & 0.431 & 0.427 \\
\hline 15 & 0.440 & 0.442 & 0.440 & 0.441 & 0.433 & 0.419 & 0.407 & 0.393 & \\
\hline 20 & 0.437 & 0.434 & 0.420 & 0.397 & 0.395 & 0.381 & 0.380 & 0.371 & -- \\
\hline
\end{tabular}


A- تأثير درجة الحرارة على تفاعل الاكسدة واستقرارية صبغة الازور لقد تضمنت هذه الفقرة دراسة تأثير درجات حرارية مختلفة (15-25-35 م) أولاً في تفاعل اكسدة المركبين الدوائيين كبريتات السالبيوتامول وحامض الميفيناميك بمدة زمنية مقدارها 10 دقائق وثانياً في استقرارية الصبغة بقياسها عند 606.5 نانوميتر بعد خمس دقائق من التخفيف إلى حد العلامة تحت الظروف المثلى المستحصل عليها من التجارب السابقة حيث اوضحت النتائج في الأشكال (3 و4) أن درجة حرارة 25 م كانت هي المثلى في التقدير إذ تم الحصول على أقصى امتصاص بعد 10 دقائق من بدء التفاعل وباستقرارية لا تقل عن ساعة لذا اعتمدت في الدراسات اللاحقة.

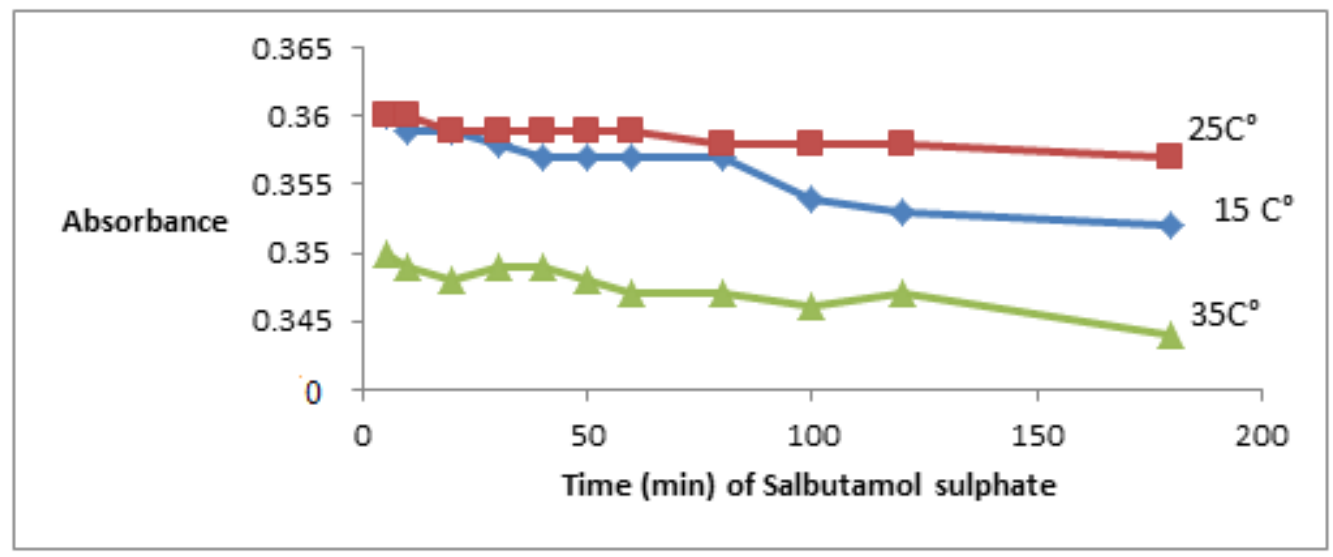

الثكل (3) تاثير درجة الحر ارة على امتصاصية صبغة الازور - عند تقدير كبرينات السالبيونامول

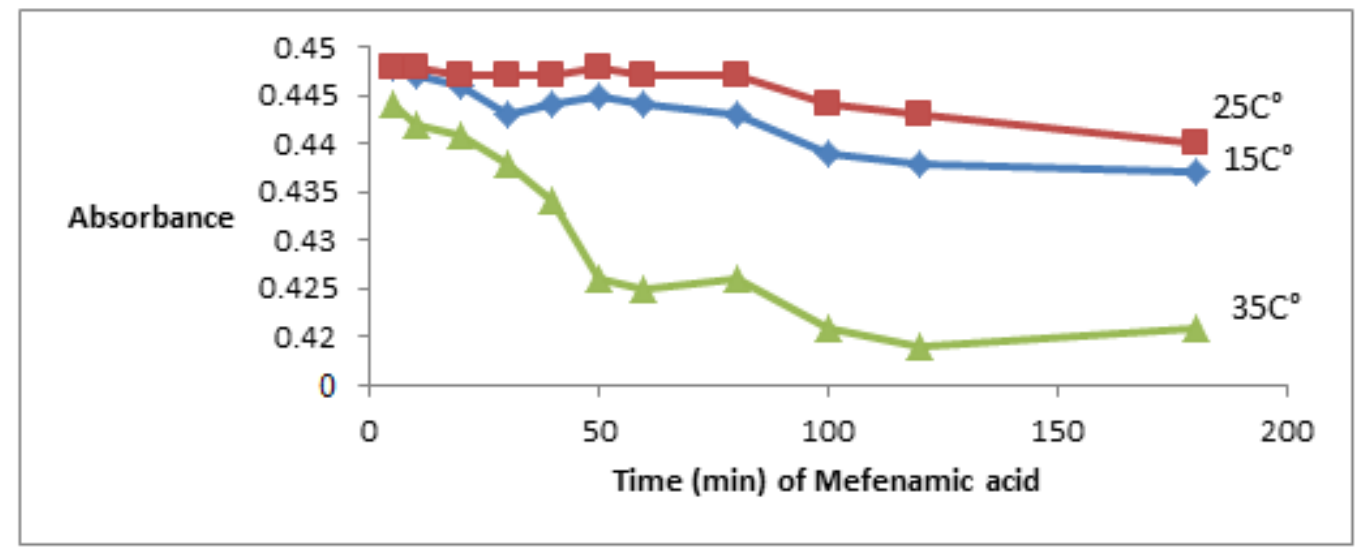

الثكل (4) تأثير درجة الحرارة على امتصاصية صبغة الازور A- عند تقدير حامض الميفيناميك

تأثير المواد الفعالة سطحياً

درس تأثير اضافة انواع مختلفة من مواد فعالة سطحياً (موجبة، سالبة، متعادلة) ومدى تأثيرها على امتصاصية صبغة الازور -

A لتقدير كل من كبريتات السالبيوتامول وحامض الميفيناميك وبينت النتائج التي تم تثبيتها في الجدول (10) أن كل المواد الفعالة سطحياً أدت إلى انخفاض في الطول الموجي والامتصاص لهذا تم استبعادها في التجارب اللاحقة. 


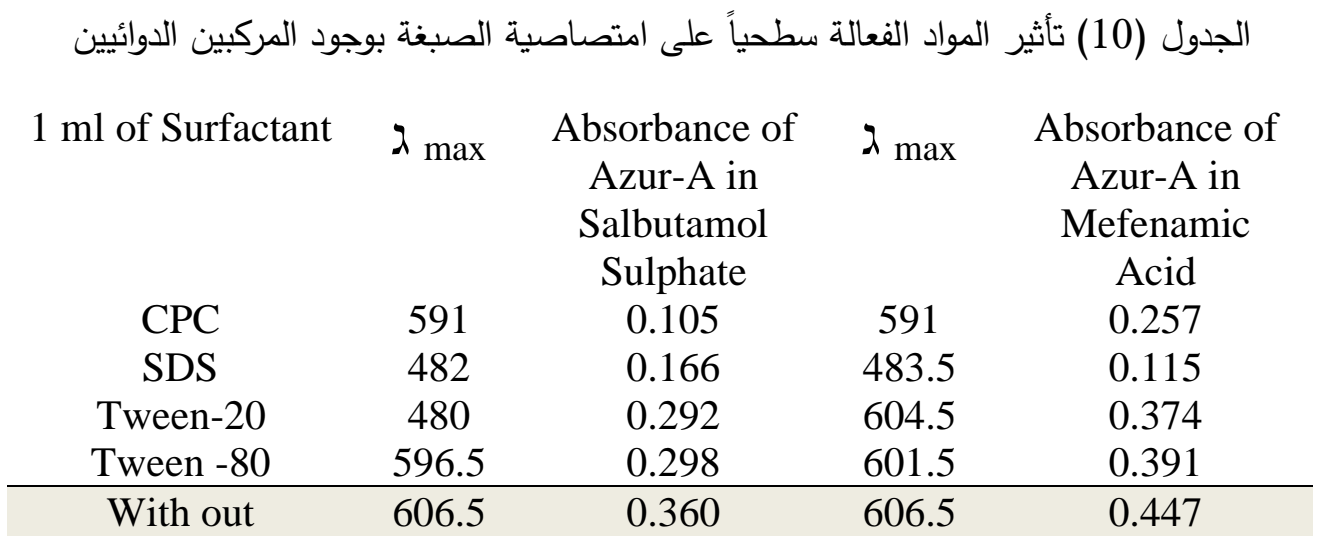

تأثير تسلسل الاضافة

الجدول (11) يبين أن تسلسل الاضافة (1) المتبع في تثبيت الظروف المثلى للمركبات الدوائية المدروسة هو الانسب في التقدير وأن حدوث اي تغير في تسلسل الاضافة يؤثر سلباً على التقدير. الجدول (11) تأثير تسلسل الاضافة

Order Reaction of Absorbance of Azur-A in presence of number component Salbutamol Mefenamic Acid

\begin{tabular}{llcl}
\multicolumn{4}{c}{ sulphate } \\
\hline 1 & $\mathrm{D}+\mathrm{A}+\mathrm{Nb}+\mathrm{ZA}$ & 0.360 & 0.447 \\
2 & $\mathrm{~A}+\mathrm{Nb}+\mathrm{D}+\mathrm{ZA}$ & 0.331 & 0.390 \\
3 & $\mathrm{Nb}+\mathrm{A}+\mathrm{D}+\mathrm{ZA}$ & 0.330 & 0.395 \\
4 & $\mathrm{Nb}+\mathrm{ZA}+\mathrm{D}+\mathrm{A}$ & 0.331 & 0.373
\end{tabular}

Azur-A (ZA) المركب الدو ائي، (A) (N) - بروموسكسينميد الحامضي، (D)*

طيف الامتصاص النهائي لصبغة الأزور

حال الانتهاء من تثبيت الظروف المثلى تم رسم طيف الامتصاص النهائي لتقدير المركبات الدوائية المدروسة عن طريق

تفاعل الصبغة مع العامل المؤكسد N - بروموسكسينميد مرة بوجود دواء كبريتات السالبيوتامول 8 مايكروغرام/مللتر ومرة بوجود دواء حامض الميفيناميك 8 مايكروغرام/مللتر والاشكال (5) و(6) توضح الحزم الامتصاصية للمركبين الدوائيين. 


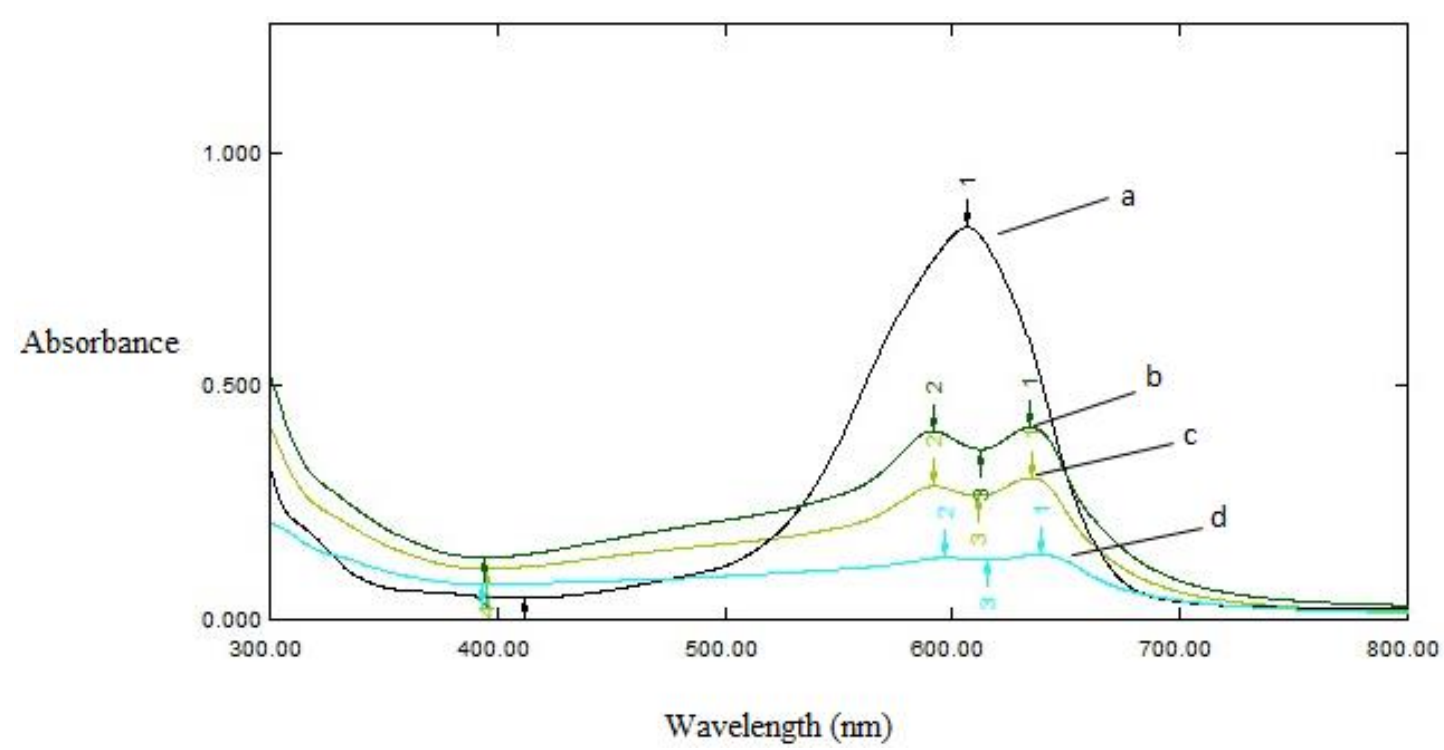

الثكل (5) - طيف امتصاص 18 مايكروغرام/ملتر من صبغة الازور -A المذابة بالماء المقطر مقابل الماء المقطر ، (b - طيف الامتصاص النهائي لصبغة الازور-A بوجود العامل المؤكسد N- بروموسكسينميد وبوجود 8 مايكروغرام/مللتر من كبريتات السالبيوتامول ضد الماء المقطر ، c - ضد المحلول الصوري وd - المحلول الصوري ضد الماء المقطر )

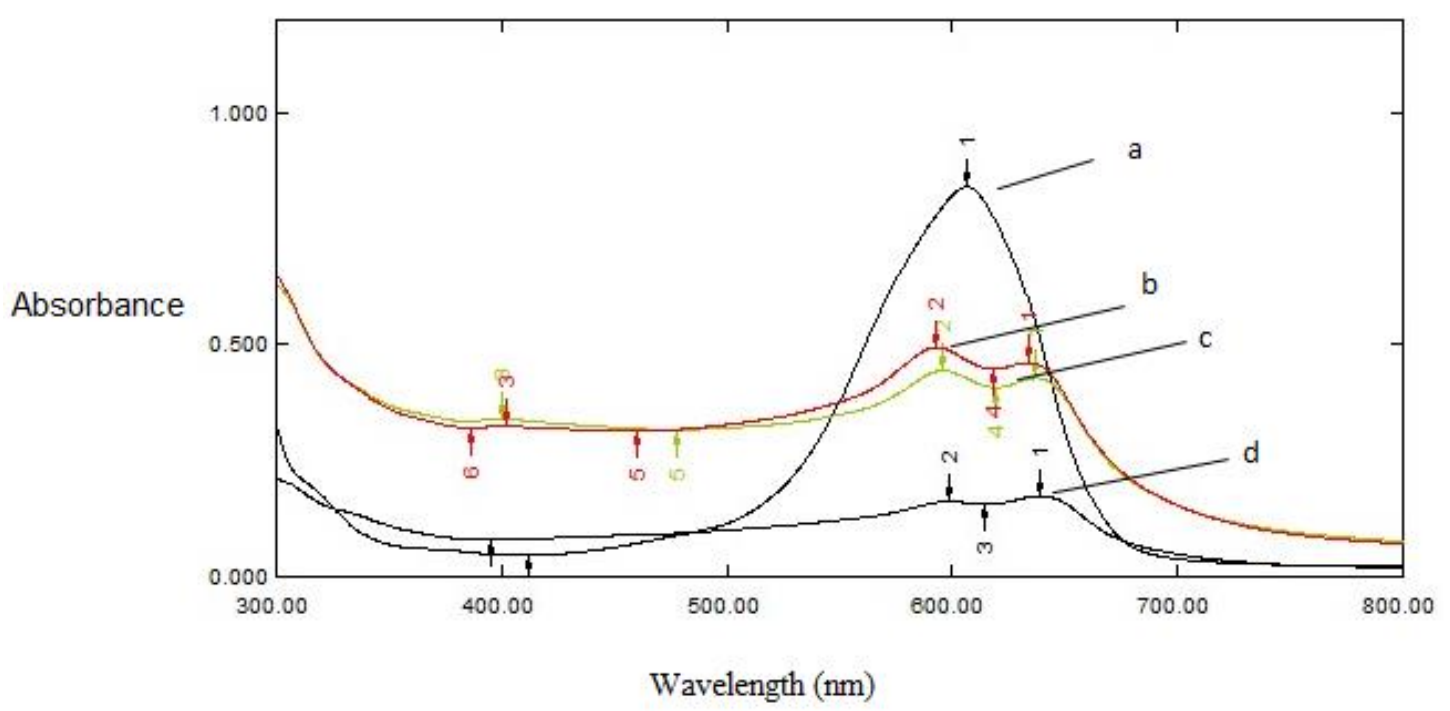

الثكل (6) - طيف امتصاص 18 مايكروغرام/مللتر من صبغة الازور -A الدذابة بالماء المقطر مقابل الماء المقطر، (b- طيف الامتصاص النهائي لصبغة الازور -A بوجود العامل المؤكس N- بروموسكسينميد وبوجود 8 مايكروغرام/مللتر حامض الميفيناميك ضد الماء المقطر ، c- ضد المحلول الصوري وd- المحلول الصوري ضد الماء المقطر ) والثكل (7) يوضح المنحنيات القياسية للمركبين الدوائيين والذي يشير إلى امكانية تقدير 1.6 -12.8 و1.6 - 13.6 مايكروغرام /ملتر لكل من كبريتات السالبيوتامول وحامض الميفيناميك على التوالي وأن هناك انحرافاً سلبياً بعد الحدود التقديرية العليا إذ بلغت قيمة معامل التقدير للمنحنيات القياسية (0.9989، 0.9983) لكل من كبريتات السالبيوتامول وحامض الميفيناميك على 
التوالي مما يدل على انها تمتلك مواصفات خطية ممتازة فيما بلغت الامتصاصية المولارية 2.3×10 4 و 8.1013 3 لتر .مول-1.1. 1 لكل من كبريتات السالبيوتامول وحامض الميفيناميك على التوالي مما يدل على الحساسية العالية للطريقة ويبين الجدول (13) ملخص المعطيات التحليلية لتقدير كلا المركبين الدوائيين.

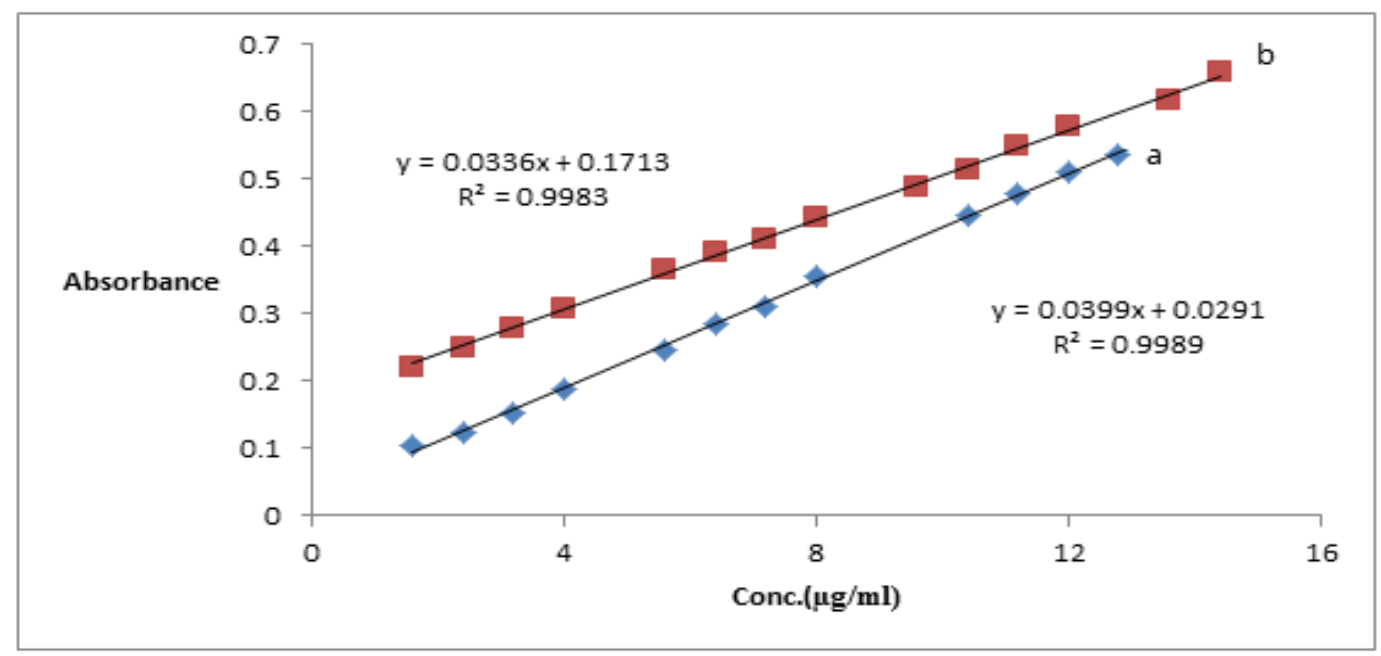

الثكل (7) المنحني القياسي لتقدير (a) كبريتات السالبيوتامول، b- حامض الميفيناميك)

تم حساب حدود الكثف والتقدير الكمي بأخذ مكررات للبلانك وقياس الامتصاص لها مقابل الماء المقطر وبتطبيق المعادلة

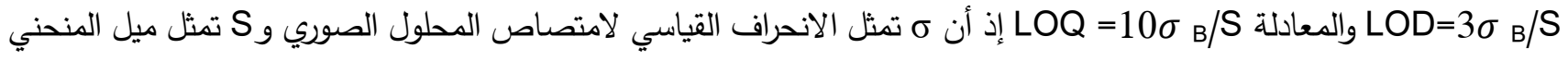
القياسي [28].

\section{دقة الطريقة وتوافقها}

تم حساب دقة الطريقة وتوافقها عن طريق حساب نسب الاسترجاع والانحراف القياسي النسبي لخمس مكررات عند ثلاثة تراكيز مختلفة لكلا الدوائيين حامض الميفيناميك وكبريتات السالبيوتامول وكما في الجدول (12) حيث بين أن الطريقة ذات دقة وتوافق جيدين إذ إن معدل نسبة الاسترجاع كان 56 .100\% و 100.74\% لكل من كبريتات السالبيوتامول وحامض الميفيناميك على التوالي في حين كان معدل الانحراف القياسي النسبي RSD أقل من 1.1\% بالنسبة لكبريتات السالبيوتامول وأقل من \% 2.8 لحامض 
الجدول (12) دقة الطريقة وتوافقها

\begin{tabular}{cccccc} 
Drug & $\begin{array}{c}\text { Amount } \\
\text { added } \\
(\mu \mathrm{g} / \mathrm{ml})\end{array}$ & $\begin{array}{c}\text { Amount } \\
\text { found } \\
(\mu \mathrm{g} / \mathrm{ml})\end{array}$ & $\begin{array}{c}\text { Recovery* } \\
\%\end{array}$ & $\begin{array}{c}\text { Average } \\
\text { Recovery } \\
\%\end{array}$ & $\begin{array}{c}\text { RSD* } \\
\%\end{array}$ \\
\cline { 1 - 4 } Salbutamol & 4 & 3.95 & 98.75 & & 1.07 \\
sulphate & 8 & 8.19 & 102.37 & 100.56 & 0.73 \\
& 12 & 12.07 & 100.58 & & 0.36 \\
Mefenamic & 4 & 4.026 & 100.65 & & 2.70 \\
acid & 8 & 8.14 & 101.75 & 100.74 & 1.56 \\
& 12 & 11.98 & 99.83 & & 0.75
\end{tabular}

* Average of five determinatioms.

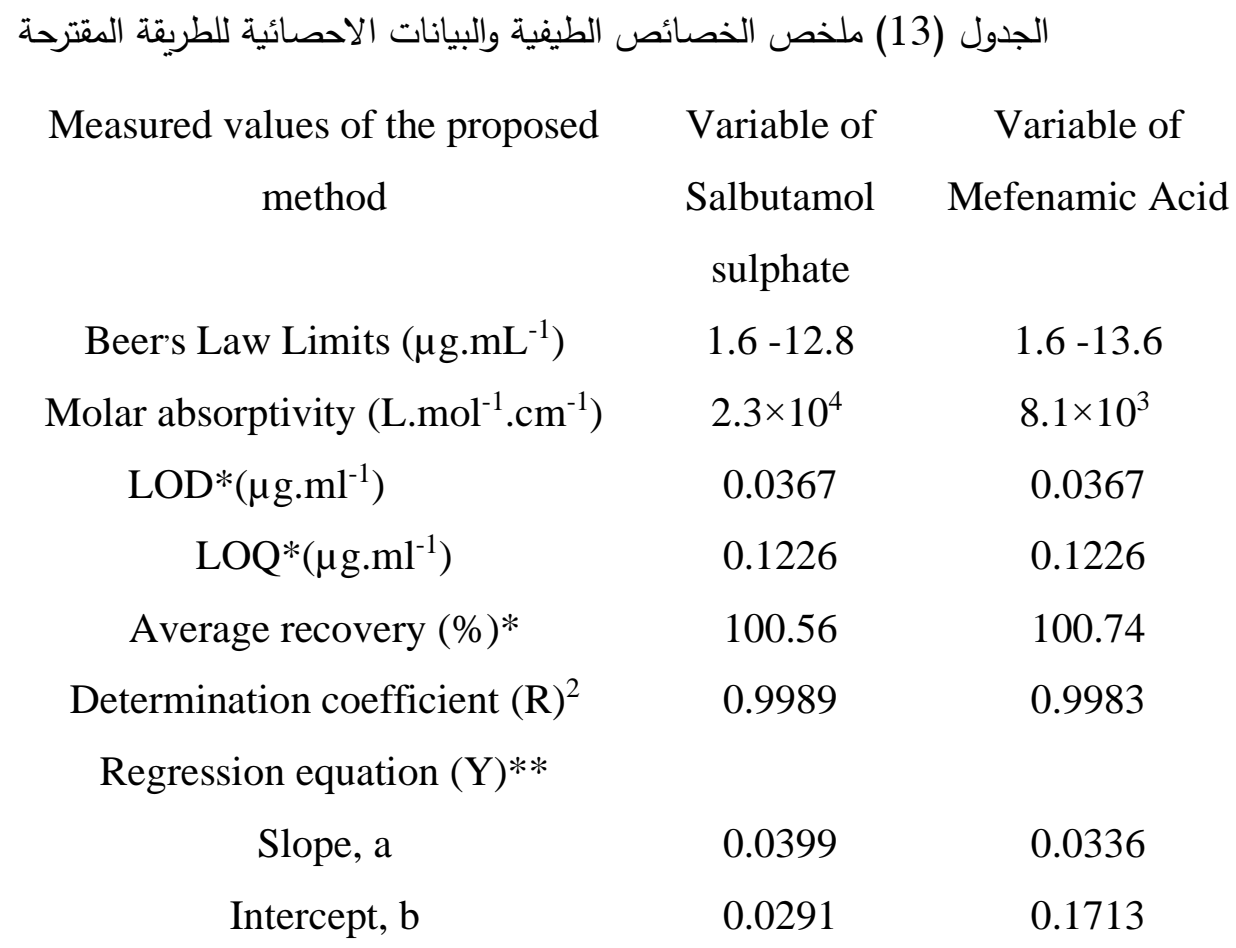

*Average of five determinations.

$* * \mathrm{Y}=\mathrm{aX}+\mathrm{b}$, where $\mathrm{X}$ is the conc. of Salbutamol sulphate or Mefenamic Acid

التفاعل الكيميائي المقترح

من متابعة الادبيات والبحوث الحركية وميكانيكية التفاعلات [31,30,29 نلاحظ ان المركب N- بروموسكسينميد يعد

عملا مؤكسدا وعامل برومة في الوسط الحامضي للمركبات العضوية الاليفاتية والاروماتية لذا افترض حدوث برومة للمركبين الدوائيين

المدروسين كبريتات السالبيوتامول وحامض الميفيناميك بواسطة الكمية المحسوبة من N- بروموسكسينميد مع بقاء جزء غير متفاعل

من العامل المؤكسد، يتبع ذلك اضافة الكمية المعلومة من صبغة الازور -A اذ يتم اكسدتها بالكمية المتبقية من العامل المؤكسد ويؤدي

الى قصر لونها ويقاس امتصاص المتبقي من الصبغة عند الطول الموجي 606.5 نانوميتر والذي يتناسب خطيا مع تركيز كلا

المركبين الدوائيين، كما هو موضح في الميكانيكية المقترحة التالية: 
<smiles>CC(C)(C)NCC(O)c1ccc(O)c(CO)c1</smiles>

Salbutamol sulphate<smiles>Cc1cccc(Nc2ccccc2C(=O)O)c1C</smiles>

Mefenamic Acid<smiles>O=C1CCC(=O)N1Br</smiles><smiles>[CH2-]</smiles>

$\mathrm{N}$-bromosuccinimide

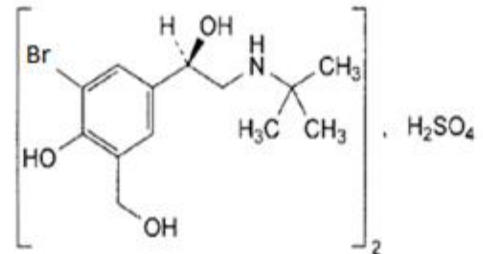<smiles>Cc1cc(Br)cc(Nc2ccccc2C(=O)O)c1C</smiles>

N-bromosuccinimide

Azur-A + Unreacted N-bromosuccinimide

Colourless (oxidative destruction)

The absorbance of residual dye measured at $606.5 \mathrm{~nm}$

\section{تطبيق الطريقة المقترحة على المستحضرات الصيدلانية للمركبين الدوائيين}

طبقت الطريقة المقترحة على المستحضرات الصيدلانية كبريتات السالبيوتامول وحامض الميفيناميك ويمكن الاستتناج من
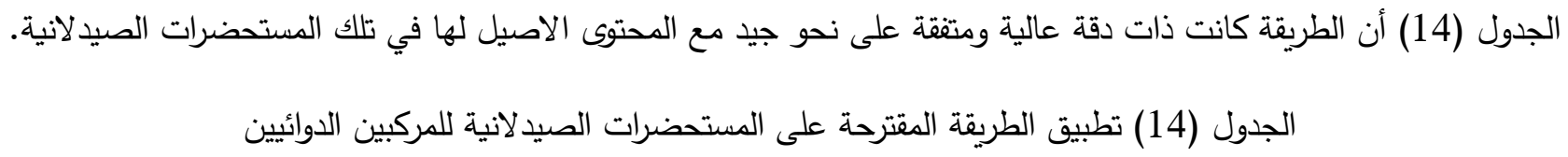

$\begin{array}{cccccc}\begin{array}{c}\text { Pharmaceutical } \\ \text { Preparation }\end{array} & \begin{array}{c}\text { Certified } \\ \text { value } \\ (\mathrm{mg})\end{array} & \begin{array}{c}\text { Drug } \\ \text { amount } \\ \text { present } \\ (\mu \mathrm{g} / \mathrm{ml})\end{array} & \begin{array}{c}\text { Recovery* } \\ (\%)\end{array} & \begin{array}{c}\text { Average } \\ \text { drug } \\ \text { content } \\ \text { found } \\ (\mathrm{mg})\end{array} & \begin{array}{c}\text { RSD* } \\ (\%)\end{array} \\ \begin{array}{c}\text { BUTADIN } \\ \text { Tablets }\end{array} & 2 & 8 & 102.2 & & 0.98 \\ \begin{array}{c}\text { SDI.IRAQ } \\ \text { BUTADIN }\end{array} & & 10.4 & 100.95 & 2.03 & 0.50 \\ \quad \begin{array}{c}\text { Syrup } \\ \text { SDI.IRAQ }\end{array} & 2 & 4 & 97.50 & & 1.70 \\ \begin{array}{c}\text { MEFSTAN } \\ \text { Capsules }\end{array} & 250 & 12 & 99.34 & 1.96 & 0.34 \\ \text { Haryana-INDIA } & & 8 & 102.5 & & 1.17 \\ \text { PONAMEC } & & 4 & 100.74 & 254.05 & 3.2 \\ \text { Tablets } & 500 & 8 & 101.23 & & 1.7 \\ \text { MVC-INDIA } & & & 102.5 & 509.32 & 3.6\end{array}$

*Average of five determinations. 
تقييم نتائج الطريقة المقترحة

لأجل اثبات نتائج الطريقة الطيفية المطورة ومدى نجاحها في تقدير المركبين الدوائيين المدروسين وخلوهما من تداخل المضافات للشركات المصنعة في المستحضرات الصيدلانية وبسبب عدم توفر متطلبات واجهزة الطريقة القياسية للدستور البريطاني [5] استخدمت طريقة الاضافة القياسية بالطريقة المقترحة على المستحضرات الصيدلانية لكبريتات السالبيوتامول وحامض الميفيناميك كما في الثكل (8) و(9).

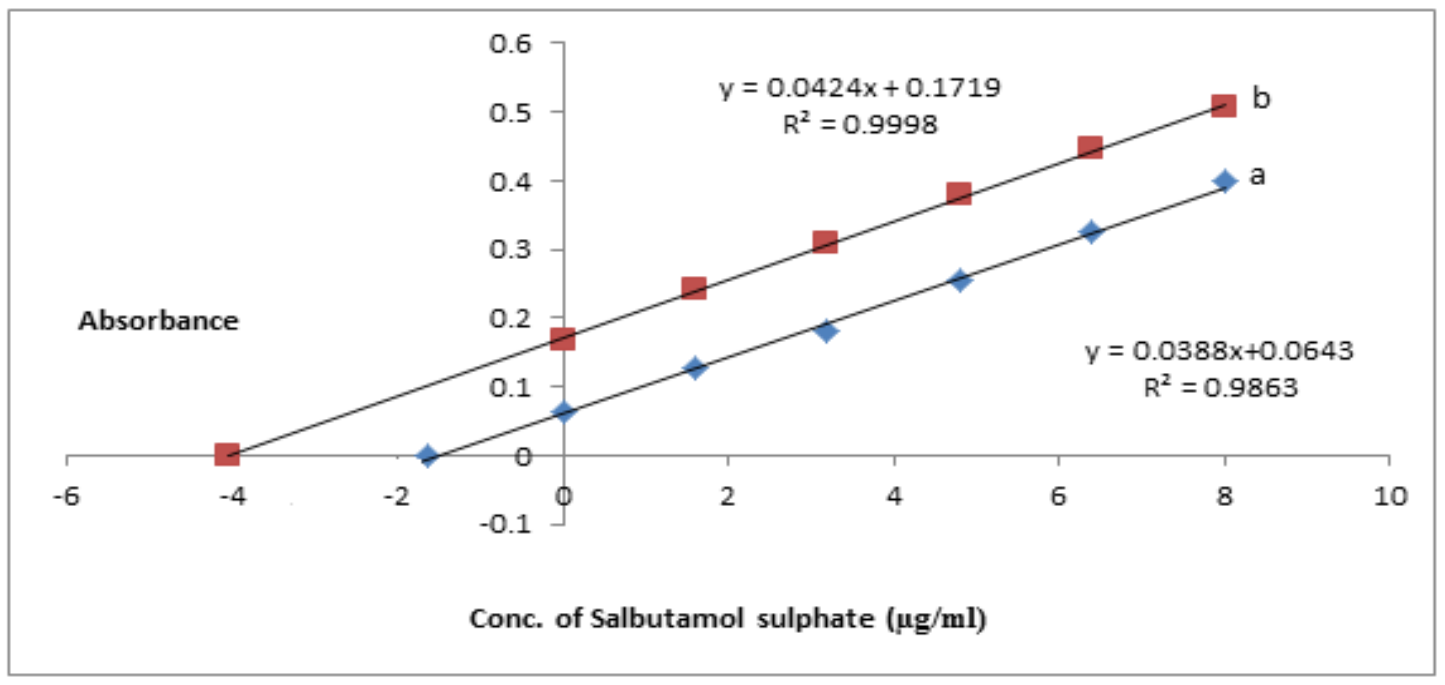

الثكل (8) منحني الاضافة القياسية لتقدير كبريتات السالبيوتامول في (a - 1.6 مايكروغرام/ملتر مستحضر الأقراص عراقية المنشأ)، (-b 4 مايكروغرام/مللتر مستحضر المحلول عراقي المنشأ)

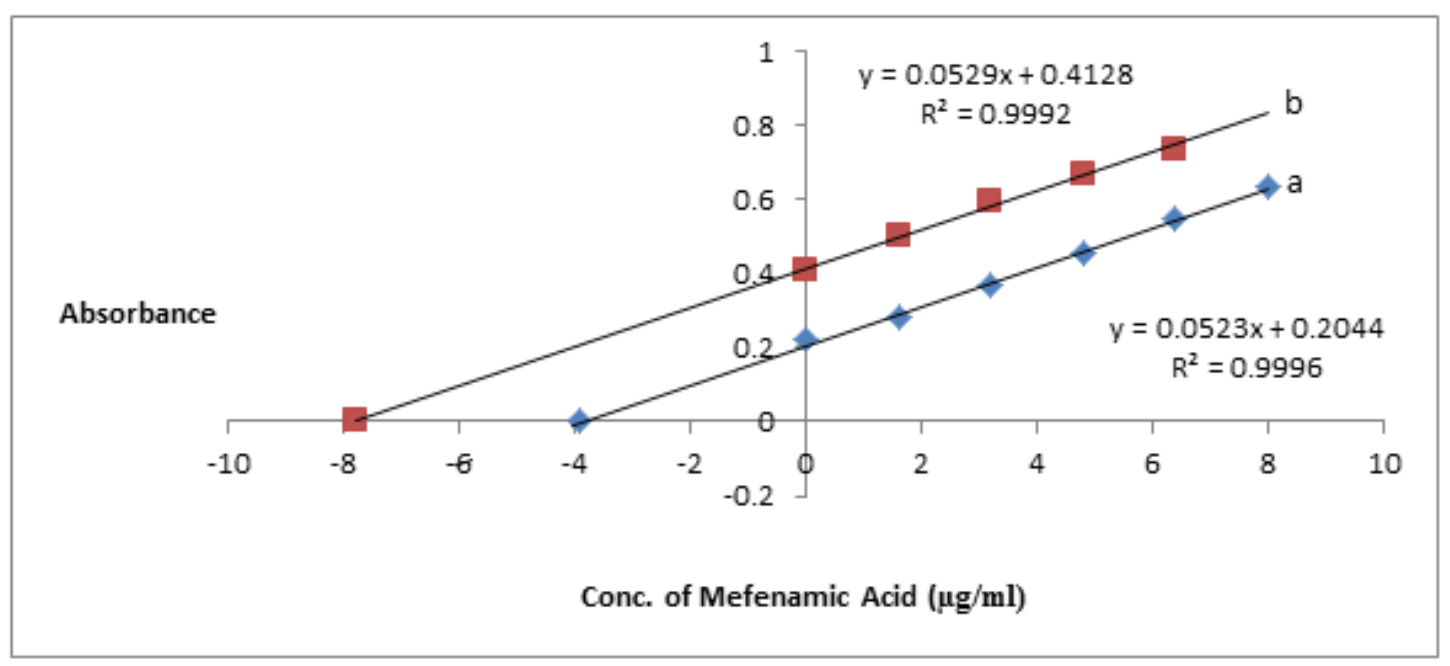

الثكل (9) منحني الاضافة القياسية لتقدير حامض الميفيناميك في (a- 4 مايكروغرام/مللتر مستحضر الكبسول هندي المنشأ)، (-b) 
ادرجت النتائج في الجدول (15) والتي بينت أن طريقة الاضافة القياسية متفقة على نحو جيد مع الطريقة المقترحة ضمن

$$
\text { المدى المقبول للخطأ مما يدل على أن الطريقة ذات انتقائية جيدة. }
$$

جدول (15) مقارنة دقة الطريقة المقترحة لتقدير كبريتات السالبيوتامول وحامض الميفيناميك في المستحضرات الصيدلانية مع طريقة الاضافة القياسية

$\begin{array}{ccccc}\text { Pharmaceutical } & \text { Certified } & \text { Amount } & \begin{array}{c}\text { Recovery } \\ (\%) \text { of }\end{array} & \begin{array}{c}\text { Drug content } \\ \text { Found } \\ \text { preparation }\end{array} \\ \begin{array}{c}\text { Value } \\ (\mathrm{mg})\end{array} & \text { Taken } & \begin{array}{c}\text { Standard } \\ \mathrm{mg} / \mathrm{ml}\end{array} & \text { Addition } & (\mathrm{mg})\end{array}$

\begin{tabular}{|c|c|c|c|c|}
\hline \multirow{2}{*}{\multicolumn{5}{|c|}{$\stackrel{\text { BUTADIN }}{=} \quad$ BUTA }} \\
\hline & & & & \\
\hline త్ $\quad$ SDI & 2 & 1.6 & 103.57 & 2.07 \\
\hline \multicolumn{5}{|l|}{ IRAQ } \\
\hline \multirow{2}{*}{\multicolumn{5}{|c|}{$\begin{array}{c}\text { Tablets } \\
\text { BUTADIN }\end{array}$}} \\
\hline & & & & \\
\hline SDI & 2 & 4 & 101.35 & 2.027 \\
\hline \multicolumn{5}{|l|}{ IRAQ } \\
\hline \multirow{2}{*}{\multicolumn{5}{|c|}{$\begin{array}{c}\text { Syrup } \\
\text { MEFSTAN }\end{array}$}} \\
\hline & & & & \\
\hline BRAWN & 250 & 4 & 97.70 & 244.25 \\
\hline \multicolumn{5}{|l|}{ INDIA } \\
\hline \multicolumn{5}{|l|}{ Capsules } \\
\hline PONAMEC & & & & \\
\hline MVC-INDIA & 500 & 8 & 97.54 & 487.71 \\
\hline Tablets & & & & \\
\hline
\end{tabular}

اقترحت طريقة طيفية غير مباشرة لتقدير كبريتات السالبيوتامول وحامض الميفيناميك والتي اعتمدت على برومة المركبين

الدوائيين بوجود العامل المؤكسد N- بروموسكسينميد في الوسط الحامضي وتقدير غير المتفاعل من العامل المؤكسد مع كمية ثابتة من محلول صبغة الازور - A مؤدياً إلى قصر لونها عند درجة حرارة 25 مْْ، وتم تطبيق الطريقة على المستحضرات الصيدلانية للمركبين المدروسين بنجاح وبدقة وتوافق جيدين حيث وجد أن نتائج الطريقة تتوافق مع المحتوى الاصيل للمستحضر الصيدلاني ومع نتائج طريقة الاضافة القياسية للطريقة المقترحة.

\section{REFERENCES}

1. A. Lipman, (1993), " Martindale -the Extra Pharmacopoeia", $30^{\text {th }}$ ed. Edited by J.E.F.Reynolds. International Journal of Pharmacy Practice. 2, 1255.

2. J. Egle, (1986)," The pharmaocological basis of therapeutics", $7^{\text {th }}$ ed. Edited by G. Alferd, L. Goodman, T.Rail and F. Murad, Macmillan, New York, NY 18. Journal of Pharmaceutical Sciences, 75,829. 
3. P. Van Eenoo and F. Delbeke, (2002), "Detection of inhaled salbutamol in equine urine by ELISA and GC/MS^2". Biomedical Chromatography:BMC. 16, 513-516.

4. P. Cobelens, A. Kavelaars, A. Vroon, M. Ringeling, R. Zee, W. Eden and C. Heijnen, (2002), " The $\beta 2$-adrenergic agonist salbutamol potentiates oral induction of tolerance, suppressing adjuvant arthritis and antigenspecific immunity", J. Immunol, 169(9), 5028-5035.

5. British Pharmacopoeia, (2013), CD-ROM, system simulation, the stationery office Ltd., London.

6. A. Goth, (1978), " Medical pharmacology principle and concepts", 9 ${ }^{\text {th }}$ Edn., the C.V. Mosby Company Printied in United State of America, 392-400.

7. C. R. Craig and R.E. Stitzel, (1997), "Modernpharmacology with clinical applications", $5^{\text {th }}$ Edn. Little Brown and Company, Boston , 329.

8. Medicinal Chemistry, (2003), "Staff members of the medical chemistry department", Mansoura University Faculty of Pharmacy, 82.

9. M. Ebadi, (2007), "Desk reference of clinical pharmacology", $2^{\text {th }}$ Edn., CRC Bress Taylor and Francis gruop, London, 41.

10.T. Al-Sabha, (2007),"Development of spectrophotometric methods for assay salbutamol in pharmaceutical formulation", J. Edu. and Sci.,19, 25-35.

11. A. Khaleel, M. Bakir and A. Aziz, (2013),"Spectrophotometric determination of salbutamol by oxidative coupling reaction with $\mathrm{N}, \mathrm{N}$-dimethyl para phenylene diamine dihydrochloride in the presence of potassium ferricyanide in basic medium", Karbala Journal of pharmaceutical sciences, 4(5): 170-182.

12. H. Al-Hafith, (2005), "Development of spectrophotometric methods for the determination of some phenolic compounds and catecholamines in pharmaceutical preparations", MSc. Thesis. University of Mosul. (In Arabic)

13. M. Al-Enizzi, T. Al-Sabha and T. Al-Ghabsha, (2012), " Use of charge transfer complex formation reaction in spectrophotometric microdetermination of some drugs", Jordan Journal of Chemistry, 7(1): 87-102.

14.Y. Issa, A. Shoukry and R. El-Nashar, (2001)," Conductimetric determination of reproterol HCl and pipazethate $\mathrm{HCl}$ and salbutamol sulphate in their pharmaceutical formulations", Journal of pharmaceutical and Biomedical Analysis, 26, 379-386.

15. R. Gupta, H. Fuller and M. Dolovich, (1994), " Optimization of a column liquid chromatographic procedure for the determination of plasma salbutamol concentration ", Journal of Chromatography Biomedical Sciences and Applications, 654, 205-211.

16. N. S. Othman and L.S. Awadis, (2009), "Spectrophotometric determination of mefenamic acid in pharmaceutical preparations via arsenazo Ш - cerium(Ш) reaction", J. Raf. Sci., 20(1): 8-21.

17. N.S. Othman and L.S. Awades, (2008), "Spectrophotometric determination of mefenamic acid via oxidative coupling reaction with 4-ammino-antipyrine in presence of $\mathrm{N}$ - chlorosuccinimide", Pak.J. Anal. Environ . Chem., 9(2):64-68.

18. Y. Cem and T. Keziban, (2000), "pH Induced difference spectrophotometric assay of paracetamol and mefenamic acid in tablets", FABAD J. Pharm. Sci., 25, 91-95.

19. S.B. Dikran, M.I. Al-Joboury and A.K. Mohammed, (2014)," Spectrophotometric determination of mefenamic acid in pharmaceutical preparations", Ibn Al-Haitham J. For Pure \&Appl. Sci., 27(3). 
20. H.A. Zadeh, F. Morshedzadeh and E. Rahimpour, (2014), "Trace analysis of mefenamic acid in human serum and pharmaceutical wastewater samples after pre-concentration with $\mathrm{Ni}$-Al layered double hydroxide nano-particles", J.of Pharm. Analysis, 4(4):331-338.

21. A. Niazi, M.D. Torkman and N. Khorshidi, (2015), "Spectrophotometric determination of mefenamic acid in biological sample using magnetic iron oxide nanoparticles as a sorbent for solid phase extraction", J. of Nanoanalysis, 2(2), 46-56.

22. M. Mahadik, S. Dhaneshwer and R. Bhavsar, (2011), "Ahigh performance liquid chromatographytandem mass spectrometric method for the determination of mefenamic acid in human plasma:application to pharmacokinetic study", (wileyonlinelibrary.com) Dol 10.1002/bmc. 1777.

23. P.P. Dahivelkar, S.B. Bari, S. Bhori and M. Bhagwat, (2009)," High performance liquid chromatographic estimation of drotaverine hydro-chloride and mefenamic acid in human plasma", Iranian J. of Pharm. Res., 8(3): 209-215.

24. A.T. Gowda and N.M. Made, (2000), " Application of azur-a in the spectr-ophotometric determination of penicillin drugs", Trans. Illinois State Academy of Sci., 93, 1, 39-45.

25. E.L. Kean, (1968), "Rapid, sensitive spectrophotometric method for quantitative determination of sulfatides", J. Lipid Res.9(3): 319- 27.

26. A.J. Al-Hadidi, (2019)," Spectrophotometric determination of mesalazine, terbutaline sulphate and chlorpromazine hydrochloride in pharmaceutical preparations", MSc. Thesis, University of Mosul. (In Arabic)

27. G.L. Al-Ramadhani, (2019),"Spectrophotometric and fluorometric deter-mination of mesalazine and tetracycline", MSc. Thesis, University of Mosul. (In Arabic)

28. M. Valcarcel, (2000)," Principles of analytical chemistry", Springer-Veralg , Berlin, Germany, 67.

29. B. Naragana, K. Divya and P.S. Nayak, (2013)," Selective and valiated spectrophotometric methods for the determination of midazolam using N-bromosucinimide", J.Chem. Pharma. Research, 5(4):268-274.

30. A. Mohammed, (2019), "Spectrophotometric and fluorimetric determin-ation of some drug compounds using tiron reagent, nile blue, rose bengal and acriflavine dyes", Ph.D. Thesis, University of Mosul. (In Arabic)

31. M.Y. Al-Meshaekhy, (2017), "Development of spectrophotometric methods and atomic absorption in drug compounds analysis using different reactions", Ph.D. Thesis, University of Mosul. (In Arabic). 